\title{
Techniques for managing the reclamation regime of agricultural landscapes in southern Kazakhstan
}

\author{
Yuri Bezborodov ${ }^{1 *}$, Kudaybergen Beysenbin ${ }^{2}$, Nyetbay Khozhanov ${ }^{2}$, and Zhibek \\ Auganbaeva ${ }^{2}$ \\ ${ }^{1}$ Russian State Agrarian University - Moscow Timiryazev Agricultural Academy, Moscow, the \\ Russian Federation \\ ${ }^{2}$ Taraz regional university named after M.Kh. Dulaty, Taraz, the Republic of Kazakhstan
}

\begin{abstract}
The article considers the mechanisms of rational natural resources management aimed at technical and technological modernization of agricultural industry as well as at natural resources recovery. The interrelationship of factors participating in the formation of ground-level microclimate, the soil forming process and the hydrogeological regime has been studied. Research Methods. The radiation index $\left(\mathrm{R}_{H}\right)$ has been proposed to be used for managing the soil and ameliorative conditions of lands. The classification of irrigated lands in the steppe zone has been proposed as well, it is based on the radiation index values. research finding and general conclusion. Thus, there are identified three agricultural zones and three farming systems respectively: neutral, optimal and risky. The main characteristics of the identified farming systems are given. The irrational use of energy resources has resulted in accelerated degradation of the natural environment and desertification of the territory, which in its turn affects the sustainability of steppe agriculture and leads to the deterioration of soil fertility and decrease in gross yields. The necessity to proceed to a new level of scientifically based assessment of bioenergy resources and to develop new farming models, principles and methods of farming system has been shown.
\end{abstract}

\section{Introduction}

It is well known that in recent years in all regions of the agro-industrial complex there have been recorded both serious reduction in efficiency of economic activity and severe environment degradation. This result from both the lack of a mechanism for the rational use of natural resources and of capital investments aimed at its technical and technological modernization, and at the restoration of natural resources. Therefore, the study of the relationship between economic and environmental indicators in the sphere of agricultural production allows assessment of their mutual influence and developing models of environmental and economic balance between structural elements of the agro-industrial complex.

\footnotetext{
* Corresponding author: ubezborodov@,rgau-msha.ru
} 
Approaches to solving the problem of ecological and economic balance of structural elements of agro-industrial complex in arid zone should be based on a number of fundamental principles usually applied for modeling of complex systems. The assessment of regional ecological-economic balance of structural elements of agro-industrial complex was carried out using the analytical model; the quantitative relationships between individual parameters of the natural system and the vital structures of crops (root system) were taken into account.

To solve this problem, it is necessary to develop and implement information system for precise regulation of reclamation regime in agro ecosystems; which in its turn should provide the complex formation of water, nutrient, thermal and microbiological conditions of soil, as well as temperature and humidity of near surface atmosphere in order to increase the efficiency of total solar radiation. Reclamation parameters should be regulated within a certain quantitative range and time cycle, thus increasing the amount of energy returned to the soil and preserving the established ratio of energy flows, which contributes to increasing soil fertility and stability, and as a consequence, to the growth of crop yields.

At present, deterioration of the ecological situation causes devegetation of soils, which results in the negative balance of organic matter (carbon), alkaline earth metal cations $\left(\mathrm{Ca}^{2+}, \mathrm{Mg}^{2+}\right)$ and nutrients. Soil fertility depends not only on the natural properties of the soil, but it is also strongly affected by human activities in the process of land cultivation, when soil is used as a mean for growing agricultural products. So in this respect in order to improve soil fertility in the cropping system, taking into account the ecological and ameliorative conditions of irrigated regions, upgraded models of optimal soil fertility should be developed.

The relevance of the performed research is to substantiate the need to review the prospects of using water and land resources and to develop a set of farming system elements for steppe agro-landscapes based on the radiation index of the terrain altitude $(\mathrm{RH})$.

The aim of the research is to develop the scientific basis for the creation of landscape recovery farming system which is based on targeted regulation of natural processes and thus ensuring the increased share of energy (from these natural processes) is spent on the soil-formation.

The objective of the study included the development of a set of measures aimed at expanded reproduction of soil fertility due to the application of landscape recovery system of agriculture, based on more effective use of solar energy in the soil-forming process under the particular natural and climatic conditions.

\section{Methods and hypotheses}

It is out of any doubt that specification of some features of soil-forming process in arid zone is needed and technological parameters of crop farming should be scientifically substantiated. A decrease in the economic efficiency of agricultural activity and intensification of natural environment degradation recorded in all agricultural regions is the result of both the lack of rational environmental management measures and the lack of investments aimed at natural resources restoration, technical and technological modernization of these measures. In this respect the study of the economic and environmental indicators interrelationship in the sphere of agriculture makes it possible to assess the extent of their mutual influence and to develop the model of balanced design parameters of agricultural production.

The crop production zoning and specialization are also interrelated and to a large extent depend on the specific features of soil and climatic conditions of the region. 
The conceptual model of reclamation regime management was developed as a result of the analysis of long-term research on the dynamics of material and energy flows within the natural object. This model makes it necessary to update the scientific and methodological basis in the sphere of soil reclamation.

When assessing the effectiveness of reclamation impacts the certain requirements are imposed on soil indicators, which are aimed at reducing the depletion of organic matter reserves in soils and expanded reproduction of soil fertility.

The objects of the research are irrigated lands of the southern zone of Kazakhstan. Field experiments were carried out at the experimental and production plot of the department of "Land reclamation and Agronomy" of Taraz Regional University named after M.Kh. Dulaty in the period of 2011-2020.

The field experiments were conducted in accordance with the approved regional methodology. Experiments in four replications were carried out for 3 and more years, accompanied by the study of water-physical and agrochemical soil properties, salt and nutrient regimes, groundwater level and salinity, soil moisture dynamics, along with phenological observations of plant growth and development, crop yield recording, etc.

Distinctions between crop yields obtained in different experimental variants (plots) were statistically processed by method of corrected deviations.

The study of water-physical and agrochemical soil properties, as well as laboratory analyses for determining the content of water-soluble salts, humus and nutrients, were performed in accordance with the approved regional methodologies.

In addition, theoretical and empirical methods of analysis were used to justify the energy resources and regulation of agro-ameliorative processes, taking into account the bioecological changes of the environment.

\section{Results and discussion}

Climate productivity should be considered as a complex characteristic of meteorological factors positively influencing the formation of biological resources of landscapes or ecological systems. Therefore, many researchers have made the attempts to assess the influence of climate-forming factors on vegetation by means of calculating coefficients characterizing the resource availability in a natural system $[1,2,3]$.

There is currently no consensus among scientists on the predominant influence of one or another factor in crop production. Some researchers believe that in order to increase soil fertility it is sufficient to sow and to grow alfalfa on a large scale, as this crop enriches the unsaturated zone with mineral residues and contributes to improving the water-air regime of the soil. The others consider that using of water resources is quite reasonable. Therefore, for a more detailed understanding of the current situation in agriculture of the arid zone, the factors of soil forming process such as atmosphere, soil and groundwater should be taken into consideration.

It is commonly known that agricultural processes depend on the atmosphere (groundlevel microclimate), soil type and groundwater. Consequently, climatic conditions, i. e. ground-level microclimate (GLM), play the leading role in the soil forming process in arid zone, while groundwater is of highest importance in humid zone. However, there are still very few research results available on the assessment of the quantitative and qualitative composition of agro enosis in terms of regulation of agro-ameliorative processes, taking into account bio-ecological changes of the environment.

The ratio of the components forming GLM in the earth's surface layer of the irrigated zone was calculated by the authors and expressed as follows: $36 \%$ accounts for the atmosphere, $48 \%$ - for the soil and 16\% - for the hydrogeology (Fig. 1). The soil forming process is affected by the listed above factors in the following proportions: atmosphere - 
$48 \%$, soil $-32 \%$, and hydrogeology $-20 \%$ (Fig. 1b). And the groundwater regime is influenced by the atmosphere with $16 \%$ share, by soil - with $20 \%$ share and by hydrogeology - with $64 \%$ share (Fig. 1).

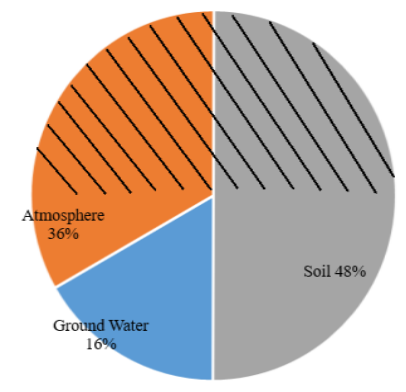

(a)

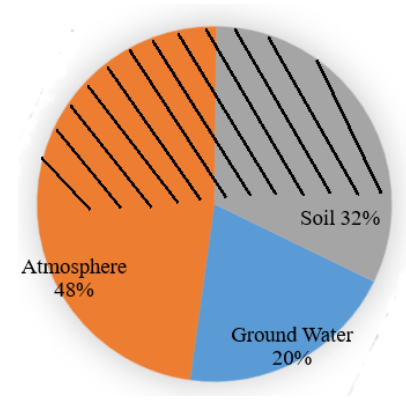

(b)

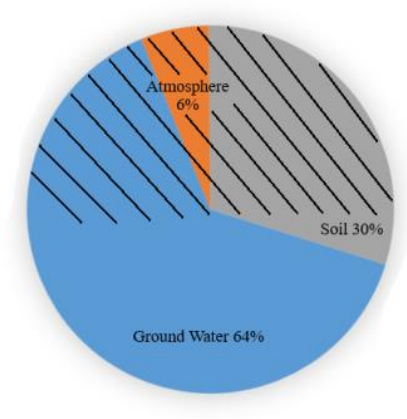

(c)

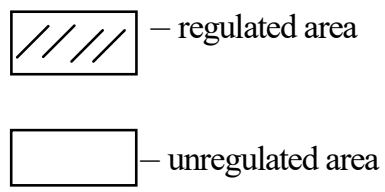

Fig. 1. The components of ground-level microclimate (in the earth's surface layer of the atmosphere), of soil forming process and of groundwater regime in arid zone.

(a) Ground-level microclimate development

(b) Soil forming process development

(c) Groundwater regime development

The performed analysis demonstrates that the components of the main soil forming factors influencing a particular object are not the same. Thus, the effects of the external factors (such as agricultural practices, land reclamation, etc.) must be strictly differentiated for each specific case. Therefore, in theory for stabilizing the ground-level microclimate, one can control in regulated zone $25 \%$ of atmospheric parameters and $25 \%$ of soil parameters (Fig. 1a); in soil forming process the same ratio (Fig. 1b) can be controlled respectively; for regulation the groundwater regime one can control $16 \%$ of the atmospheric parameters, $20 \%$ of the soil parameters (60-40\% where $40 \%$ are unregulated), $24 \%$ of the hydrogeological parameters (where $10 \%$ are unregulated) (Fig. 1c).

Hence, according to our research the main components contribute to the reclamation regime of soils in arid zone in the following proportion: total solar radiation (42\%), soil fertility $(15 \%)$, soil salinity $(9 \%)$, air temperature $(9 \%)$, air humidity $(8 \%)$, precipitation $(4 \%)$, wind speed $(4 \%)$, water supply $(3 \%)$, groundwater salinity $(1 \%)$, lithological structure of soils (1\%) and irrigation water salinity (1\%).

The increase in area of poor and very poor land categories requires further improvement of the theoretical foundations of agro-ecological reclamation monitoring in agricultural production.

Land reclamation monitoring is primarily aimed at tracking the reclamation status of agricultural lands and in particular at the soil salinity. Studies have shown that, depending on the degree of soil salinity, the reduction in gross crop yield may be as high as $96 \%$. For this reason combating soil salinization must be an issue of the utmost importance and the first necessity. The problem of soil salinity in land reclamation science is considered in conjunction with agricultural practices, which provides an obstacle in establishing a 
qualitative indicator of a particular factor. We estimate that soil salinity contributes $9 \%$ to the regulation of the soil forming process. Consequently, in the biosphere the principles of development of the main factors should be formed depending on the qualitative and quantitative composition of the agrochemical-biophysical index of soils.

So, reclamation activities performed on irrigated lands cannot be considered as a unified approach. They should conform to each specific irrigated area, depending on climatic, geomorphological, hydrogeological, soil-reclamation factors, irrigation water quality, etc., which influence soil fertility and crop yield.

When cultivating crops on reclaimed lands, two indicators are of greatest interest they are temperature and air humidity. These indicators, according to our estimates, account for 9 and $8 \%$, respectively, in the formation of reclamation regime of irrigated lands.

Long-term agro-climatic data collected on Kazakhstan territory indicate that the sum of effective temperatures (above $100{ }^{\circ} \mathrm{C}$ ) during the growing season varies within 1900-2300 ${ }^{\circ} \mathrm{C}$. Thereby, about $170-210{ }^{\circ} \mathrm{C}$ is spent on the soil forming process, and the rest part of effective temperatures participates in the accumulation of the biological mass in the vegetation cover of the earth's surface.

The research has shown that under the conditions of the southern zone of Kazakhstan the maximum depth of solar radiation penetration reaches $30-35 \mathrm{~cm}$. Thus, this depth is considered to be the area intensively influenced by soil forming process.

So, in order to substantiate the methods for evaluating the soil forming process with respect to the agro-ecological state of irrigated lands, a new approach to the soil forming process in agricultural production has been proposed, the principal scheme of which is presented in Figure 2.

Figure 2 shows that in development of the reclamation regime of irrigated lands the components are divided into the following sub-zones: atmospheric $67 \%$, soil $25 \%$ and water $8 \%$.

Based on the heart of the problem, the development of agro-meliorative and agrotechnical measures is strongly influenced by atmospheric processes. Therefore, in order to substantially improve the current state of irrigated lands, agro-climatic resources should be analyzed in depth, especially under the increasingly arid climate conditions. According to M.I. Budyko [3], by the year 2025 the average global temperature will be likely to rise by $2.5^{\circ} \mathrm{C}$; by 2050 - by about $3-4{ }^{\circ} \mathrm{C}$, and the amount of precipitation will increase by $50-200$ $\mathrm{mm} /$ year.

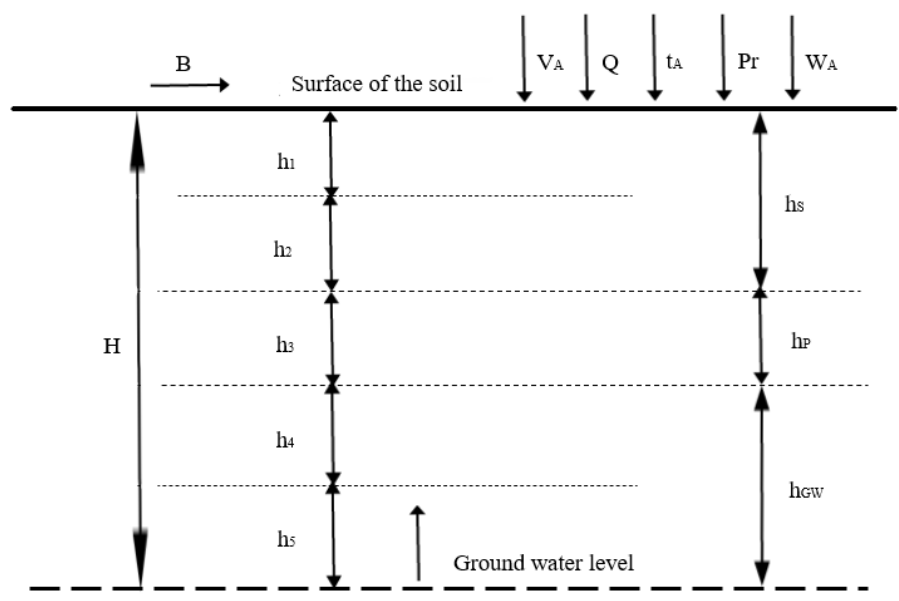

Fig. 2. Principle scheme of the soil forming process on irrigated lands of the steppe zone of Kazakhstan. 
$\mathrm{h}_{1}$ - zone of active solar radiation penetration, $\mathrm{cm}$.

$\mathrm{h}_{2}$ - zone of impact of air temperature variability, $\mathrm{cm}$.

$\mathrm{h}_{3}$ - area of groundwater discharge.

$\mathrm{h}_{4}-$ permanent capillary wetting zone, $\mathrm{cm}$

$\mathrm{h}_{5}-$ zone of seasonal fluctuation of the groundwater level, $\mathrm{cm}$.

The authors have proposed to use the radiation index $\left(\mathrm{RH}_{\mathrm{H}}\right)$ values depending on the terrain elevation (altitude of the area), which is calculated as follows:

$$
R_{H}=R / H
$$

It allows making relevant and rapid qualitative assessment of the actual state of irrigated land in the steppe zone. The index has been calculated for the two administrative regions of the South Kazakhstan and the obtained values are shown in Table 1. It has become necessary to further improve the methodology for managing soil-reclamation criteria according to the site-specific energy resources, the ecological, ameliorative and economic aspects of irrigated agriculture and the radiation index data being considered.

Table 1 demonstrates that the ratio of the radiation index to the altitude of the terrain varies within the interval $0.22-2.37$, and further in the article it is described as a measure of the radiation index depending on the terrain altitude [1-4]. Consequently, the $\mathrm{RH}_{\mathrm{H}}$ values are not the same in the same soil and climatic zone, and this constitutes grounds to suggest that the agro technical and reclamation measures applied for obtaining high crop yields have not proven successful. The irrational use of bioenergy potential determined the differences in the ratio of radiation index to the absolute altitude of the terrain $(\mathrm{RH})$.

Table 1 shows that a significant change in the radiation index of the terrain altitude (values fluctuate within the range of $0.3-2.0$ ) provides the basis for a zonal classification of farming systems in the steppe zone (Figure 3):

1. neutral farming system zone $\left(\mathrm{R}_{\mathrm{H}}>20\right.$ and more);

2. optimal farming system zone $\left(\mathrm{RH}_{\mathrm{H}}=0.3-2.0\right)$;

3. risky farming system zone $\left(\mathrm{RH}_{\mathrm{H}}<0.3\right)$.

Table 1. Radiation index of the terrain altitude, RH.

\begin{tabular}{|c|c|c|c|c|}
\hline No. & $\begin{array}{c}\text { Terrain } \\
\text { altitude, } \mathrm{m}\end{array}$ & $\begin{array}{c}\text { Radiation } \\
\text { balance, } \mathrm{kJ} / \mathrm{cm}^{2}\end{array}$ & Precipitation, $\mathrm{mm}$ & $\begin{array}{c}\text { Radiation index value } \\
\text { per unit of terrain } \\
\text { altitude }\end{array}$ \\
\hline \multicolumn{5}{|c|}{ Turkistan Region } \\
\hline 1 & 316 & 305.3 & 186 & 0.96 \\
\hline 2 & 206 & 453.5 & 238 & 2.20 \\
\hline 3 & 789 & 481.1 & 951 & 0.61 \\
\hline 4 & 237 & 503.6 & 275 & 1.17 \\
\hline 5 & 543 & 636.1 & 582 & 1.99 \\
\hline 6 & 238 & 475.5 & 264 & 0.80 \\
\hline \multicolumn{7}{|c|}{ Zhambyl Region } \\
\hline 7 & 350 & 279 & 174 & 1.18 \\
\hline 8 & 455 & 536 & 179 & 0.66 \\
\hline 9 & 742 & 490 & 161 & 0.41 \\
\hline 10 & 952 & 382 & 150 & 2.37 \\
\hline 11 & 1135 & 240 & 153 & 0.57 \\
\hline 12 & 207 & 490 & 187 & 181 \\
\hline 13 & 832 & 471 &
\end{tabular}

The arguments listed above allow concluding that long-term crop cultivation has been ineffective despite sufficient solar radiation and warmth supply. The respond of different 
crops to $\mathrm{RH}$ varies significantly, this fact has not previously been taken into account when zoning agricultural production and justifying involvement of a particular crop in rotation [5-11]. So, the development of farming systems classification based on radiation index of terrain altitude becomes reasonable (Table 2).

Table 2. Classification of farming systems.

\begin{tabular}{|c|c|c|}
\hline Absolute terrain altitude, $\mathrm{H}$ & $\begin{array}{c}\text { Radiation index of the } \\
\text { absolute terrain altitude, } \mathrm{RH}\end{array}$ & Zone of farming system \\
\hline $0-100$ & $>2.0$ & neutral \\
\hline $100-450$ & $0.3-2.0$ & optimal \\
\hline $451-1200$ & $<0.3$ & risky \\
\hline
\end{tabular}

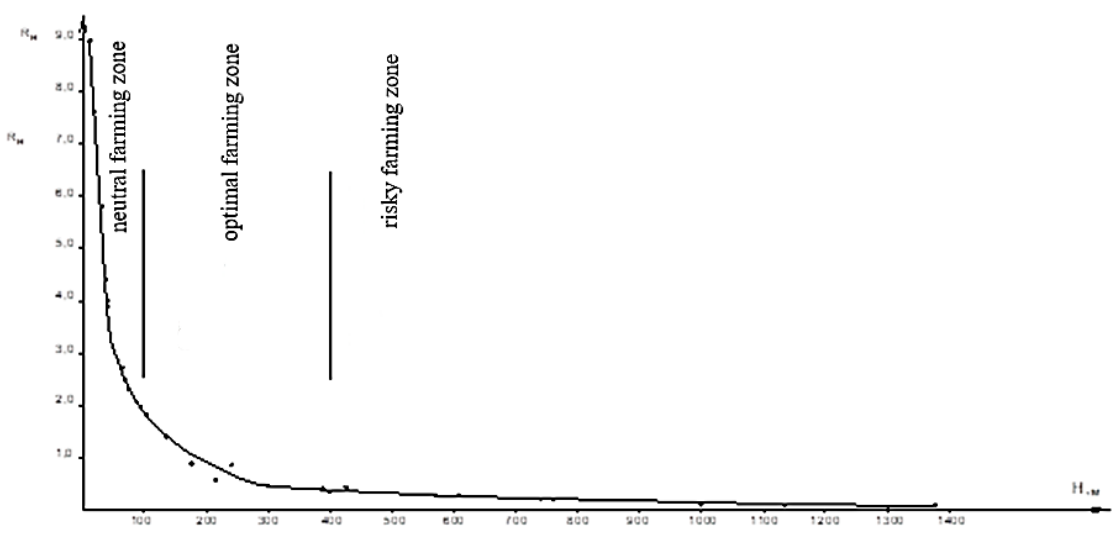

Fig. 3. Dependence of the radiation index on the absolute terrain altitude.

The data in Table 2 indicate that for the environmental sustainability of steppe agricultural landscapes the following limits and measures have been developed for arable lands as elements of such agro-landscapes:

1. In the neutral farming system zone the arable lands are appropriate for intensive use to grow crops according to the agricultural specialization. In order to obtain organic production, the main elements of agricultural landscape should be brought into agreement with the natural and economic conditions, and the necessary environment protection activities should be planned. Arable lands are used intensively with the aim to reap the harvest 2-3 times per year. The use of intensive agricultural system in the steppe zone is risky, as there is a high probability of a significant reduction in soil productivity of arable lands; however, the high proportion of perennial grasses in crop rotation ensures the soil-protecting and conservation function.

2. In the optimal farming system zone a wide range of intensive technologies and a set of agrotechnical and special measures to protect the soil from water and wind erosion is supposed to be applied. This combination of measures along with biological protection techniques is aimed at enhancing soil fertility recovery. There also can be used alternative farming systems which are characterized by:

1) transition from intensive agriculture to organic farming;

2) implementation of recycling and reusing in agricultural production;

3) increase in the profitability of agricultural production.

3. In the risky farming system zone only $50 \%$ of arable lands is supposed to be allocated to intensive crop cultivation. For soil fertility maintenance and recovery the high rates 
of organic and mineral fertilizers should be applied. Scientifically based agricultural practices in fact depend on weather conditions. The advantages of this system are:

1) increased profitability of agricultural production;

2) application of increased rates of fertilizers results in the growth of organic matter content, which in its turn contributes to the increase in the soil moisture content, thus preserving soil structure and as a consequence reducing soil erosion;

3) minimization of technological operations number due to process combination;

4) reduction of non-productive waste of working time.

Thus, the necessity to revise the structure of crops arrangement with respect to the radiation index of the absolute terrain altitude of the area becomes obvious, as far as the existing cultivation technologies do not correspond to the proposed classification of farming systems.

The methodology suggested by the authors for managing the reclamation regime of steppe agro-landscapes can potentially increase their productivity.

\section{Conclusions}

The current ecological and reclamation state of the irrigated lands of the steppe zone requires revision and modernization of the structure, arrangement and proportion of cultivated crops depending on the terrain altitude of the area, moreover, the existing cultivation technologies, which has exhausted the possibility of increasing soil fertility, need to be improved as well.

Continuous irrational exploitation of energy resources has led to intensified adverse anthropogenic effect on the environment, further degradation is resulting in desertification of the territory, which could not but affect the sustainability of steppe agriculture. As a consequence, soil fertility decreases and gross yields are reduced.

So, currently there is a need to proceed to a new level of scientifically based assessment of bioenergy resources, to develop the new models of agriculture, principles and methods of farming systems.

The proposed approach to the rationale for applied farming systems depending on the altitude of the area, allows us to identify the reserves of soil fertility and to increase its level.

In the current circumstances on the basis of analysis of ecological, ameliorative and economic aspects of irrigated agriculture in Kazakhstan one should develop technologies for adaptive landscape agriculture predicated on the radiation balance; such technologies are supposed to regulate soil-ameliorative parameters and to ensure the rational use of land, water and energy resources at a particular site.

\section{References}

1. V. Savich, V. Chernikov, G. Podvolotskaya. Information and energy assessment of soil solutions and surface waters. Vestnik BSAU, № 2. Pp.14-17 (2016)

2. M.C. Morató, M.T. Castellanos, P. L. Aguado, A.M. Tarquis. Application of generalized Hurst dimension rose plot in terrain altitude analysis. Applied Mathematical Modelling 81(B4) (2020)

3. BudykoM.I. Evaporation in natural conditions. Hydrometeoizdat. 136p (1998)

4. Khozhanov N.N., Masatbaev M.K., Abdeshov K.B., Elyubaev S.Z., Tursunbaev Kh.I., Musabekov K.K., Energy concept for the development of farming system, Proceedings of Gorsky State Agrarian University, No. 55 (part 1), pp. 20-26 (2018)

5. Bezborodov Yu.G., Khozhanov N.N., Auganbaeva Zh.S., Assessment of the 
productivity of the reclamation agro landscapes of Zhambyl region, Prirodoobustrojstvo, No. 4, pp. 22-27 (2020)

6. Khozhanov N.N., Tursunbaev Kh., Masatbayev M., Nurabayev D. Assis P. Empirical relationships of humus formation in soils in arid zone of Kazakhstan, International journal of science and research, Vol. 8, Iss. 12 (2018)

7. Khozhanov N.N., Tursunbaev Kh.I., Masatbayev M.K., Khozhanova G.N. Evaluation of empirical links of humus formation with energy factors in the arid zone of Kazakhstan (abstract), Izvestia National'noj akademii nauk Respubliki Kazahstan, Seria agrarnyh nauk, Vol. 1, No. 49, pp. 40-45 (2019)

8. Khozhanov N.N., Bezborodov Yu.G., Masatbaev M.K., Assessment of energy linkages in the rhizosphere of a degraded soil ecosystem, Proc. Jubilee Intern. Sci. and Pract. Conf., Vol. 1 (2019)

9. Agricultural Land Improvement: Amelioration and Reclamation, B. S. Maslov, Russian Academy of Agriculture Sciences, Russia, Agricultural Land Improvement: Amelioration and Reclamation - Volume 1 No. of Pages: 448

10. The Necessity for Development of Land Reclamation, V.V. Shabanov, Moscow State University of Environmental Engineering, Moscow, Russia, Agricultural Land Improvement: Amelioration and Reclamation - Volume 1 No. of Pages: 448

11. Hindrances and Restrictions to Farming V.V. Shabanov, Moscow State University of Environmental Engineering, Moscow, Russia A.I. Golovanov, Moscow State University of Environmental Engineering, Moscow, Russia,79 Amelioration and Reclamation - Volume 1 No. of Pages: 448 